\title{
Contribution of Ultrasound-Guided Ilioinguinal/Iliohypogastric Block To Intraoperative Anesthesia In Children - Randomized Controlled Study
}

\author{
Ilke Kupeli,, ${ }^{1, *}$ and Senol Bicer ${ }^{2}$ \\ ${ }^{1}$ Anesthesiology and Reanimation Department, Erzincan University, Erzincan, Turkey \\ ${ }^{2}$ Paediatric Surgery Department, Erzincan University, Erzincan, Turkey \\ "Corresponding author: Ilke Kupeli, Erzincan University, Mengucek Gazi Training and Research Hospital, Erzincan, Turkey. Tel: +90-4462122020, E-mail: \\ ilkeser2004@gmail.com
}

Received 2017 December 14; Revised 2017 December 29; Accepted 2018 March 04.

\begin{abstract}
Objectives: The aim of this study was to investigate the effect of ilioinguinal/iliohypogastric nerve block (II/IH) only supported by ketamine sedation on intraoperative anesthesia and analgesia.

Methods: A total of 60 patients aged between 2 and 6 years, were included in the study. The patients were divided into three groups: 1) the II/IH block and ketamine group, 2) the II/IH block by inserting the laryngeal mask (LMA) and sevoflurane group, and 3) the LMA and sevoflurane group. Peroperative heart rate (HR), mean arterial pressure (MAP), amount of sevoflurane used, postoperative pain scores, number of children needing rescue analgesia, and time required for the first analgesia were recorded.

Results: The patients, consisting of 34 males and 26 females had an average age of $4 \pm 1.3$ years. There was no difference in terms of HR and MAP between the ketamine + block applied group and LMA + block applied group; however, HRs were higher and MAPs were lower in the group in which no block was added but only sevoflurane maintenance was provided and the amount of sevoflurane used significantly decreased in the group supported by $(\mathrm{II} / \mathrm{IH})$ block $(\mathrm{P}<005)$. In the postoperative period, the HR, MAP and pain scores were higher in the group with no added block but this difference was significant in the first 6 hours $(\mathrm{P}<0.05)$. Rescue analgesia was applied to a fewer of patients in the groups with added blocks and nausea-vomiting occurred only in the group without block. It was observed that analgesia was needed in average for 6.1 hours in the block group to which ketamine was applied; 4.7 hours in average in the block group to which LMA was applied; and for 2.1 hours in average in the group not supported by block $(\mathrm{P}<0.05)$. Conclusion: In this study, it was determined that II/IH block added to general anesthesia or sedation in pediatric lower abdominal surgery reduced the need for intraoperative anesthesia, provided a more stable intraoperative hemodynamics and analgesia, and provided less pain scores, longer analgesia duration, and shorter analgesia need in the postoperative period.
\end{abstract}

Keywords: Children, Ultrasound-Guided Ilioinguinal/Iliohypogastric Block, Intraoperative Anesthesia

\section{Background}

Postoperative pain control continues o be an important issue in pediatric surgery and it affects the quality of recovery, family satisfaction, and surgical success. It is shown that regional anesthesia techniques reduce perioperative stress response, provide early extubation after major abdominal and thoracic surgery, reduce the number of the days at intensive care unit and provide early conversion of gastrointestinal functions (1-5).

Ilioinguinal/iliohypogastric nerve blocks (II/IH) are frequently used for analgesia and anesthesia in surgeries including the inguinal region. Applied with success, it is as efficient as the caudal block (2-6).
II/IH nerve blocks are successfully used in inguinal hernia, orchiopexy, and varicocele surgeries because it provides ipsilateral anesthesia in the inguinal region by being combined with mild general anesthesia. However, 95\% of these surgeries are performed under general anesthesia (7). The hypothesis of this study is based on the idea that without applying general anesthesia, the II / IH block can provide successful anesthesia management even when it is administered only with ketamine sedation.

\section{Objectives}

Thus, the purpose of this study is to investigate the effect of ilioinguinal/iliohypogastric nerve block supported 
only by ketamine sedation on intraoperative anesthesia and analgesia.

\section{Methods}

The study was conducted after the ethics committee approval was received with resolution no. 09/06 of Erzincan University Clinical Trials Ethics Committee (ClinicalTrials.gov.ID: NCT02990884) and written informed consents of the patients' relatives.

A total of 60 patients aged between 2 and 6 years, who had to undergo elective lower abdominal surgery, were included in the study. The patients who had a psychiatric disease, a weight of $>40 \mathrm{~kg}$, bleeding disorders, injections or wound scars in the injection site, known allergies to local anesthetics, or suffered from cardiac-pulmonaryneurological diseases, were excluded from the study.

Preoperative management: All patients were brought with established vascular access from the ward to the operating room and received premedication with $0.1 \mathrm{mg} / \mathrm{kg}$ intravenous midazolam 10 minutes before the operation. Heart rate (HR), peripheral oxygen saturation $\left(\mathrm{SpO}_{2}\right)$, and mean arterial pressure (MAP) were recorded preoperatively at the pre-anesthesia room.

Intraoperative management: After anesthesia induction with $2 \mathrm{mg} / \mathrm{kg}$ ketamine (Ketalar, Pfizer, Istanbul, Turkey) and $0.01 \mathrm{mg} / \mathrm{kg}$ atropine (Atropin Sülfat, Osel, Istanbul, Turkey) was applied to all the cases, the patients were randomly divided into groups by an anesthetist who was not included in the study. The anesthesiologist who carried out the study did not know which procedure was applied to which group. The groups were established as follows:

Group 1: Group to which ilioinguinal/iliohypogastric block was applied with $0.4 \mathrm{ml} / \mathrm{kg} 0.25 \%$ bupivacaine (Marcaine, AstraZeneca, Istanbul, Turkey) after ketamine atropine induction and in which the anesthesia maintenance was continued only by ketamine.

Group 2: Group to which the laryngeal mask (LMA) was inserted after ketamine atropine induction, ilioinguinal/iliohypogastric block with $0.4 \mathrm{ml} / \mathrm{kg} 0.25 \%$ bupivacaine was applied and in which the anesthesia maintenance was continued with sevoflurane (Sevorane Likid, Abdi İbrahim, Istanbul, Turkey) from 2 MAC and oxygen/air mixture.

Group 3: Control group: Group to which the laryngeal mask (LMA) was inserted after ketamine-atropine induction, in which the anesthesia maintenance was continued with sevoflurane from 2 MAC and oxygen/air mixture, no block was applied and postoperative analgesic was provided by iv paracetamol (Parol, Atabay, Istanbul, Turkey).
In $\mathrm{II} / \mathrm{IH}$ block application, high-frequency linear probes were used to identify the target nerves and the surrounding anatomical formations. It was placed from the peak point of iliac crest facing umbilicus. This orientation relieved the appearance of the muscular layers and the nerves on the transversus abdominis plane. After the ultrasound probe and the aseptic preparation of the injection site, 22-gauge needle was inserted in-plane. The needle was forwarded to ilioinguinal and iliohypogastric nerves. $0.4 \mathrm{ml} / \mathrm{kg} 0.25 \%$ bupivacaine was injected around the nerves (Figure 1).

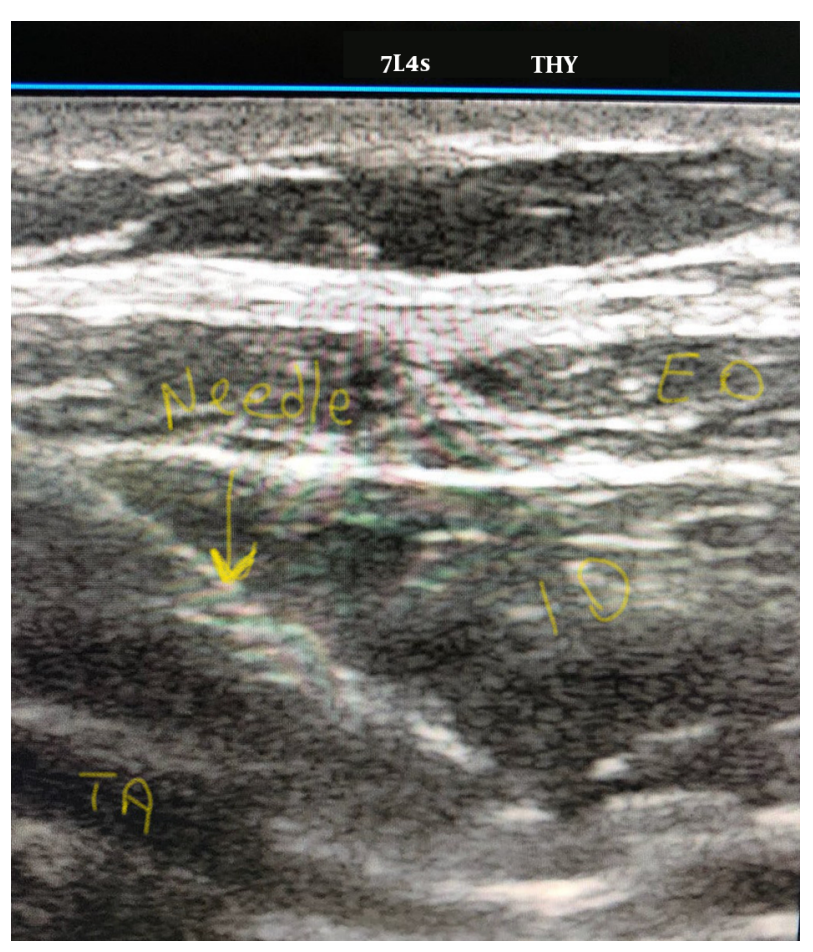

Figure 1. Picture of ultrasound guided ilioinguinal/iliohypogastric nerve block

Except for Group 3, all the surgical procedures, during which the block was applied, were started by the skin incision 20 minutes after the block application. $1 \mathrm{mcg} / \mathrm{kg}$ intravenous fentanyl was applied during skin incision, when the child moved or if an increase of $20 \%$ and more than baseline values was observed in heart rate. If the values did not return to the baseline values within 3 minutes, this dose was repeated and these patients were excluded from the study. Anesthesia depth of all the patients was measured by bispectral index (BIS) and anesthesia management was performed in such a way to keep this depth between 60 and 80 . This management was performed as follows; in the ketamine group; $25 \%$ of the first ketamine dose was administered as iv; in the group with sevoflu- 
rane maintenance, sevoflurane concentrations were increased. During the surgery; $\mathrm{HR}, \mathrm{SpO}_{2}$, MAP, BIS measurements and sevoflurane amount (ml/hour) were recorded with 5-minute intervals.

For determination of the amount of anesthetic agent consumed during the operation, the calculation formula, specified in the Drager Cato anesthesia device manual and suggested by the manufacturing company, was used: Consumption of the anesthetic agent $(\mathrm{ml} /$ hour $)=3 \times$ Fresh gas flow $(\mathrm{L} / \mathrm{min}) \times$ concentration $(\%)$.

Postoperative management: Pain assessments of the patients, who were taken to the postoperative care unit (PACU) upon completion of the surgery, were performed via modified Children's Hospital of Eastern Ontario Pain Scale (CHEOPS) and Objective Pain Scale (OPS) as 1 every 30 minutes within the first hour. When CHEOPS $\geq 6$ or OPS $\geq 5$, rescue analgesia was added with $15 \mathrm{mg} / \mathrm{kg}$ dose of IV paracetamol (8).

When all the patients were taken to the ward, $15 \mathrm{mg} / \mathrm{kg}$ paracetamol was administered to them every 8 hours.

After the patients were taken from the PACU, pain scores, $\mathrm{HR}, \mathrm{MAP}$, and $\mathrm{SpO}_{2}$ values were followed up via CHEOPS and OPS for the first 12 hours and the number of children requiring rescue analgesia, time required for first analgesia, and the presence of nausea and vomiting were recorded.

Primary purpose of the study was to test our hypothesis that II/IH block reduces the need for intraoperative anesthesia and increases intraoperative analgesia in children who undergo lower abdominal surgery.

Secondary purpose was to investigate the contribution of intraoperative II/IH block on postoperative analgesia.

Statistical analysis

It was determined in the power analysis performed by considering that this was a pilot study that a total of 60 patients were required to be included in order to have $\alpha$ $=0.05$ with $85 \%$ power.

Normal distribution was assessed by using analysis of variance, Kolmogorov-Smirnov test, skewness-kurtosis and histogram. While numerical data were presented as mean and standard deviation, categorical data were presented as numbers. Chi-square test was used to compare categorical data between the groups. In the comparison of the means between the groups, Mann-Whitney U test was used for two groups and Kruskal-Wallis test was used for comparison of three or more groups. In multiple comparisons, Tukey's HSD or non-parametric comparison tests were used. All the data were analyzed by using Statistical Package for Social Sciences (SPSS Inc., Chicago, IL) version 20.0 program. In all the analyses, statistical significance level was accepted as $\mathrm{P}<0.05$.

\section{Results}

\subsection{Demographic Data}

A total of 60 children including 34 boys and 26 girls were included in the study. Average age of the children was $4 \pm 1.3$. There was no difference among the groups in terms of gender, age, preoperative BIS, HR, MAP, and SpO2 values $(\mathrm{P}>0.05)$ (Table 1$)$.

\subsection{Intraoperative Data}

In comparison of intraoperative values among the groups, a difference was observed between MAP values in the first 10 minutes after the block application. After 15 th minute, during skin incision and after the beginning of the surgery, it was observed that heart rates were significantly different $(\mathrm{P}<0.05)$ (Table 2$)$.

When examining the difference among the groups, it was determined that there was no difference between the ketamine + block group and the LMA + block group in terms of HR and MAP. However, the difference between the block groups and the group with only sevoflurane maintenance was significant $(\mathrm{P}<0.05)$ (Table 3$)$. In general, it was observed that heart rates were higher and MAP was lower in the control group with no block and the differences were statistically significant. In the block groups, lower heart rates and higher MAP values were seen.

When examining the amount of intraoperative anesthetics, the aim of the study; it was determined that the amount of sevoflurane used, was significantly reduced in the group supported by ilioinguinal/iliohypogastric block (Table 2). In addition, no statistically significant difference was observed between the ketamine + block group and the LMA + block group in terms of the intraoperative HR and MAP measurements (Table 3).

\subsection{Postoperative Data}

As in intraoperative values, the difference among the groups in terms of postoperative values was significant ( $P$ $<0.05$ ). At all the hours monitored, the heart rates and MAP were higher in the group with no block however, this difference was significant in the first 6 hours. After the 6th hour, the heart rate and MAP were high in the group to which only sevoflurane was given but it was not statistically significant (Table 4 ).

When CHEOPS and OPS values used in the pain assessment were compared, significant differences were observed in the first 60 minutes, at 4 th and 6th hours $(\mathrm{P}<$ 0.05) (Table 4).

During follow-up, the difference between the rescue analgesia was also significant $(\mathrm{P}<001)$. In the groups to which block was applied, 5 - 6 patients needed analgesia 


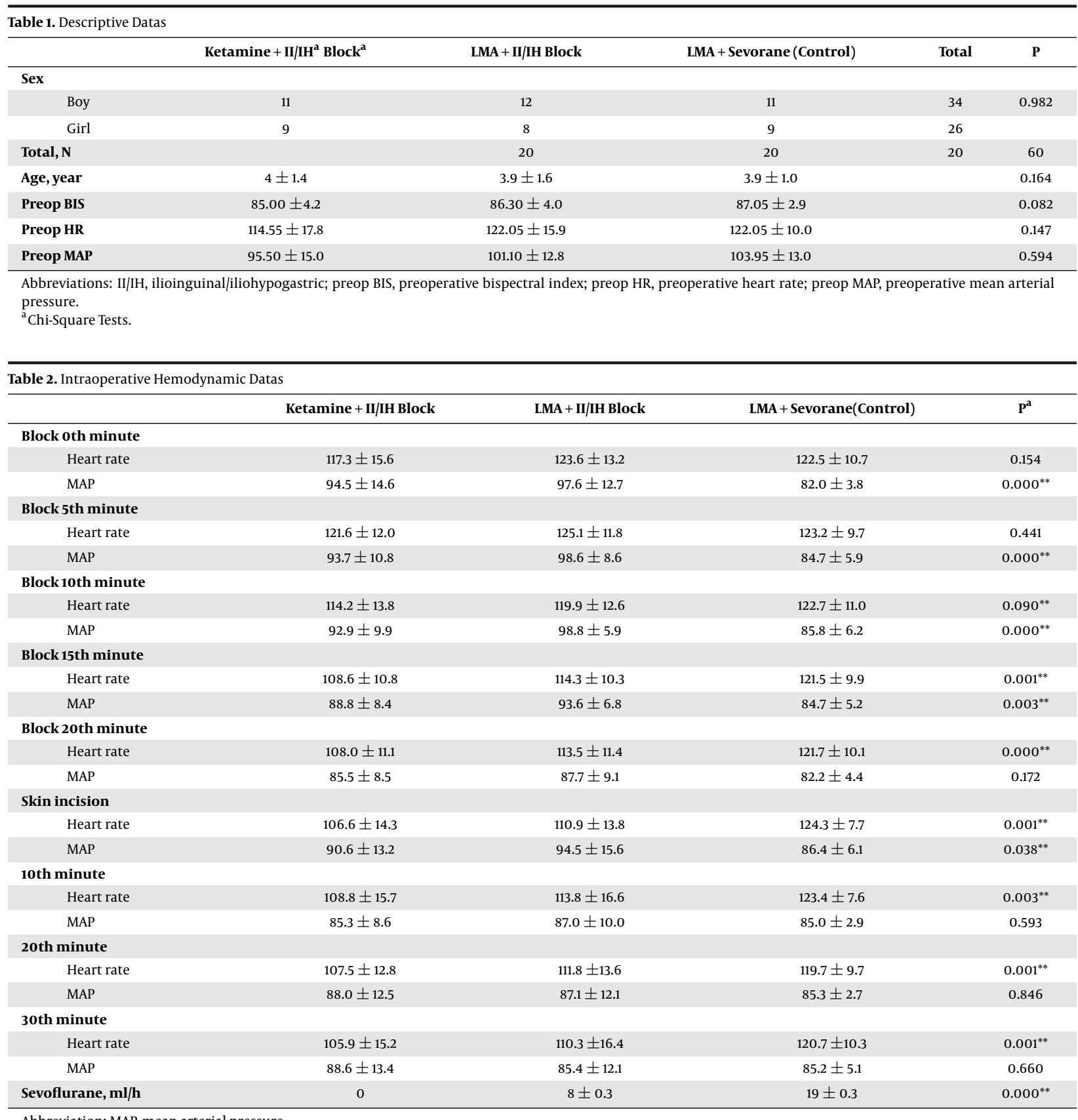

Abbreviation: MAP, mean arterial pressure.

${ }^{\mathrm{a} *}$ One way Anova, ${ }^{* *}$ The mean difference is significant at the 0.05 level.

in the early period; on the other hand, 12 patients in the group, to which no block was applied, required analgesic. Nausea and vomiting were observed only in the group with no block (Table 4).

When examining the differences among the groups, it was observed that HR, CHEOPS, and OPS values were significantly higher in the group to which only sevoflurane was administered, and in the first 6 hour $(\mathrm{P}<0.05)$ (Table 5). It was observed that the values in both groups to which block was applied, were similar.

In the first follow-up hour, it was observed that analgesia was needed averagely in 6.1 hours in the block group to which ketamine was applied; 4.7 hours in the block group to which LMA was applied; and in 2.1 hours in the group not supported by block (Table 5). 


\begin{tabular}{|c|c|c|c|c|c|c|c|c|c|}
\hline & $\begin{array}{c}\text { Ketamine + } \\
\text { II/IH Block }\end{array}$ & $\begin{array}{c}\text { LMA + II/IH } \\
\text { Block }\end{array}$ & $\mathbf{P}$ & $\begin{array}{c}\text { LMA+ } \\
\text { Sevorane } \\
\text { (Control) }\end{array}$ & $\begin{array}{c}\text { Ketamine + } \\
\text { II/IH Block }\end{array}$ & $\mathbf{P}$ & $\begin{array}{c}\text { Lma }+ \text { II/IH } \\
\text { Block }\end{array}$ & $\begin{array}{c}\text { LMA+ } \\
\text { Sevorane } \\
\text { (Control) }\end{array}$ & $\mathbf{P}$ \\
\hline \multicolumn{10}{|l|}{ o minute } \\
\hline Heart rate & $117.3 \pm 15.6$ & $123.6 \pm 13.2$ & 0.161 & $122.5 \pm 10.7$ & $117.3 \pm 15.6$ & 0.246 & $123.6 \pm 13.2$ & $122.5 \pm 10.7$ & 0.807 \\
\hline MAP & $94.5 \pm 14.6$ & $97.6 \pm 12.7$ & 0.408 & $82.0 \pm 3.8$ & $94.5 \pm 14.6$ & $0.001^{* *}$ & $97.6 \pm 12.7$ & $82.0 \pm 3.8$ & $0.000^{* *}$ \\
\hline Heart rate & $121.6 \pm 12.0$ & $125.1 \pm 11.8$ & 0.403 & $123.2 \pm 9.7$ & $121.6 \pm 12.0$ & 0.702 & $125.1 \pm 11.8$ & $123.2 \pm 9.7$ & 0.649 \\
\hline MAP & $93.7 \pm 10.8$ & $98.6 \pm 8.6$ & 0.087 & $84.7 \pm 5.9$ & $93.7 \pm 10.8$ & $0.002^{* *}$ & $98.6 \pm 8.6$ & $84.7 \pm 5.9$ & $0.000^{* *}$ \\
\hline \multicolumn{10}{|l|}{ 10th minute } \\
\hline Heart rate & $114.2 \pm 13.8$ & $119.9 \pm 12.6$ & 0.200 & $122.7 \pm 11.0$ & $114.2 \pm 13.8$ & 0.055 & $119.9 \pm 12.6$ & $122.7 \pm 11.0$ & 0.517 \\
\hline MAP & $92.9 \pm 9.9$ & $98.8 \pm 5.9$ & $0.029^{* *}$ & $85.8 \pm 6.2$ & $92.9 \pm 9.9$ & $0.010^{* *}$ & $98.8 \pm 5.9$ & $85.8 \pm 6.2$ & $0.000^{* * \mathrm{a}}$ \\
\hline \multicolumn{10}{|l|}{ 15th minute } \\
\hline Heart rate & $108.6 \pm 10.8$ & $114.3 \pm 10.3$ & 0.109 & $121.5 \pm 9.9$ & $108.6 \pm 10.8$ & $0.000^{* *}$ & $114.3 \pm 10.3$ & $121.5 \pm 9.9$ & $0.044^{* *}$ \\
\hline MAP & $88.8 \pm 8.4$ & $93.6 \pm 6.8$ & $0.046^{* *}$ & $84.7 \pm 5.2$ & $88.8 \pm 8.4$ & 0.088 & $93.6 \pm 6.8$ & $84.7 \pm 5.2$ & $0.000^{* *}$ \\
\hline \multicolumn{10}{|l|}{ 2oth minute } \\
\hline Heart rate & $108.0 \pm 11.1$ & $113.5 \pm 11.4$ & 0.138 & $121.7 \pm 10.1$ & $108.0 \pm 11.1$ & $0.000^{* *}$ & $113.5 \pm 11.4$ & $121.7 \pm 10.1$ & $0.030^{* *}$ \\
\hline MAP & $85.5 \pm 8.5$ & $87.7 \pm 9.1$ & 0.416 & $82.2 \pm 4.4$ & $85.5 \pm 8.5$ & 0.230 & $87.7 \pm 9.1$ & $82.2 \pm 4.4$ & $0.046^{* *}$ \\
\hline \multicolumn{10}{|l|}{ Skin incision } \\
\hline Heart rate & $106.6 \pm 14.3$ & $110.9 \pm 13.8$ & 0.269 & $124.3 \pm 7.7$ & $106.6 \pm 14.3$ & $0.000^{* *}$ & $110.9 \pm 13.8$ & $124.3 \pm 7.7$ & $0.001^{\mathrm{a} * *}$ \\
\hline MAP & $90.6 \pm 13.2$ & $94.5 \pm 15.6$ & 0.341 & $86.4 \pm 6.1$ & $90.6 \pm 13.2$ & 0.311 & $94.5 \pm 15.6$ & $86.4 \pm 6.1$ & $0.041^{* *}$ \\
\hline \multicolumn{10}{|l|}{ 10th minute } \\
\hline Heart rate & $108.8 \pm 15.7$ & $113.8 \pm 16.6$ & 0.260 & $123.4 \pm 7.6$ & $108.8 \pm 15.7$ & $0.001^{* *}$ & $113.8 \pm 16.6$ & $123.4 \pm 7.6$ & $0.035^{* *}$ \\
\hline MAP & $85.3 \pm 8.6$ & $87.0 \pm 10.0$ & 0.559 & $85.0 \pm 2.9$ & $85.3 \pm 8.6$ & 0.904 & $87.0 \pm 10.0$ & $850 \pm 2.9$ & 0.482 \\
\hline \multicolumn{10}{|l|}{ 2oth minute } \\
\hline Heart rate & $107.5 \pm 12.8$ & $111.8 \pm 13.6$ & 0.274 & $119.7 \pm 9.7$ & $107.5 \pm 12.8$ & $0.002^{* *}$ & $111.8 \pm 13.6$ & $119.7 \pm 9.7$ & $0.045^{* *}$ \\
\hline MAP & $88.0 \pm 12.5$ & $87.1 \pm 12.1$ & 0.793 & $85.3 \pm 2.7$ & $88.0 \pm 12.5$ & 0.440 & $87.1 \pm 12.1$ & $85.3 \pm 2.7$ & 0.610 \\
\hline \multicolumn{10}{|l|}{ 30th minute } \\
\hline
\end{tabular}

Abbreviation: MAP, mean arterial pressure

${ }^{\mathrm{a} *}$ Multiple Comparison, ${ }^{* *}$ The mean difference is significant at the 0.05 level.

\section{Discussion}

In this study, it was determined that II/IH block added to general anesthesia or sedation in pediatric lower abdominal surgery decreased the need of intraoperative anesthesia, provided a more stable intraoperative hemodynamics by reducing the heart rate and increasing the mean arterial pressure, and also increased both intraoperative and postoperative analgesia periods.

Regional anesthesia and analgesia techniques are frequently used in pediatric surgery practices in order to provide pain control. These methods reduce the need for parenteral opioids, enhance the quality of postoperative pain control, and increase patient and family satisfaction. Ilioinguinal/iliohypogastric nerve block is among the most frequently used ones and has been shown to be as effective as caudal block in inguinal hernia repairs (2-5). It is known that regional anesthesia reduces peri-operative stress response (8). Alsadek et al. showed that MAP and HR values were higher in the control group (9). In this study, in parallel, a more stable hemodynamics and reduced stress response to surgical stimulation were observed in both methods to which II/IH block was applied. Higher heart rates, lower MAP, and increased response to surgical stimulation were observed in the group which was not supported by block but only sevoflurane was applied to. In the study by Kim et al. it was specified that the caudal block added to general anesthesia reduced the use of intraoperative sevoflurane but this difference was not significant (10). In the present study, amount of sevoflurane used was observed as 2 times higher in the group to which no II/IOH block was added and this difference was statistically significant.

In our opinion, the lack of difference between the ketamine + II/IH block group and LMA+ sevoflurane $+\mathrm{II} / \mathrm{IH}$ block group in terms of intraoperative hemodynamics indicated that ketamine-supported II/IH block anesthesia can be used alone as a successful anesthetic technique in pediatric lower abdominal surgery. However, more extensive studies are required in this issue.

Today, there is no ideal method to identify and mea- 


\begin{tabular}{|c|c|c|c|c|}
\hline & Ketamine + II/IH Block & LMA + II/IH Block & LMA + Sevorane (Control) & $\mathbf{P}^{\mathbf{a}}$ \\
\hline \multicolumn{5}{|l|}{ PACU o minute } \\
\hline Heart rate & $106.7 \pm 16.9$ & $111.1 \pm 17.5$ & $122.2 \pm 14.6$ & $0.006^{* *}$ \\
\hline MAP & $85.3 \pm 11.5$ & $79.0 \pm 10.8$ & $89.6 \pm 4.3$ & $0.042^{* *}$ \\
\hline CHEOPS & $1.1 \pm 0.4$ & $0.7 \pm 0.5$ & $3.9 \pm 2.2$ & $0.000^{* *}$ \\
\hline OPS & $0.10 \pm 0.3$ & $0.1 \pm 0.4$ & $3.8 \pm 2.4$ & $0.000^{* *}$ \\
\hline \multicolumn{5}{|l|}{ PACU 30th minute } \\
\hline Heart rate & $109.3 \pm 13.2$ & $113.3 \pm 15.1$ & $122.7 \pm 11.3$ & $0.005^{* *}$ \\
\hline MAP & $85.5 \pm 13.9$ & $84.5 \pm 10.7$ & $87.5 \pm 6.1$ & 0.458 \\
\hline CHEOPS & $0.8 \pm 0.5$ & $0.8 \pm 0.7$ & $3.8 \pm 1.4$ & $0.000^{* *}$ \\
\hline OPS & $0.5 \pm 1.0$ & $0.7 \pm 1.0$ & $3.7 \pm 1.4$ & $0.000^{* *}$ \\
\hline \multicolumn{5}{|l|}{ PACU 60th minute } \\
\hline Heart rate & $110.7 \pm 14.4$ & $113.3 \pm 15.6$ & $121.4 \pm 11.1$ & $0.030^{* *}$ \\
\hline MAP & $87.3 \pm 10.6$ & $88.3 \pm 8.5$ & $87.2 \pm 6.2$ & 0.334 \\
\hline CHEOPS & $1.6 \pm 1.2$ & $1.7 \pm 1.2$ & $3.2 \pm 1.0$ & $0.000^{* *}$ \\
\hline OPS & $1.8 \pm 1.8$ & $2.3 \pm 1.7$ & $3.4 \pm 1.5$ & $0.031^{* *}$ \\
\hline \multicolumn{5}{|l|}{ PACU 2nd hour } \\
\hline Heart rate & $107.6 \pm 15.3$ & $115.7 \pm 14.8$ & $121.9 \pm 9.8$ & $0.006^{* *}$ \\
\hline MAP & $86.6 \pm 11.7$ & $85.3 \pm 6.8$ & $86.4 \pm 7.1$ & 0.777 \\
\hline CHEOPS & $2.3 \pm 2.6$ & $2.7 \pm 2.5$ & $3.9 \pm 1.9$ & 0.178 \\
\hline OPS & $2.2 \pm 2.7$ & $3.1 \pm 2.5$ & $3.7 \pm 2.2$ & 0.407 \\
\hline \multicolumn{5}{|l|}{ PACU 3rd hour } \\
\hline Heart rate & $107.9 \pm 14.9$ & $114.4 \pm 15.4$ & $118.9 \pm 9.9$ & $0.022^{* *}$ \\
\hline MAP & $86.4 \pm 10.6$ & $85.4 \pm 7.0$ & $85.7 \pm 4.4$ & 0.682 \\
\hline CHEOPS & $1.7 \pm 1.8$ & $2.6 \pm 1.9$ & $2.5 \pm 1.2$ & 0.411 \\
\hline OPS & $1.8 \pm 1.8$ & $2.6 \pm 2.0$ & $2.1 \pm 1.2$ & 0.553 \\
\hline \multicolumn{5}{|l|}{ PACU 4th hour } \\
\hline Heart rate & $107.5 \pm 13.3$ & $112.7 \pm 15.5$ & $120.6 \pm 8.7$ & $0.004^{* *}$ \\
\hline MAP & $84.3 \pm 10.3$ & $83.5 \pm 6.3$ & $86.2 \pm 5.5$ & 0.706 \\
\hline CHEOPS & $0.95 \pm 0.9$ & $1.7 \pm 1.0$ & $2.5 \pm 1.2$ & $0.000^{* *}$ \\
\hline OPS & $1.3 \pm 1.2$ & $2.0 \pm 1.1$ & $2.9 \pm 1.6$ & $0.005^{* *}$ \\
\hline \multicolumn{5}{|l|}{ PACU 6th hour } \\
\hline Heart rate & $108.6 \pm 15.2$ & $115.6 \pm 15.9$ & $123.6 \pm 12.2$ & $0.009^{* *}$ \\
\hline MAP & $87.3 \pm 9.8$ & $86.1 \pm 6.7$ & $89.9 \pm 4.5$ & 0.261 \\
\hline CHEOPS & $1.7 \pm 1.5$ & $2.5 \pm 2.1$ & $3.6 \pm 1.9$ & $0.022^{* *}$ \\
\hline OPS & $1.4 \pm 1.8$ & $2.2 \pm 1.5$ & $4.0 \pm 2.5$ & $0.001^{* *}$ \\
\hline \multicolumn{5}{|l|}{ PACU 8th hour } \\
\hline Heart rate & $110.4 \pm 17.0$ & $115.8 \pm 17.2$ & $122.5 \pm 12.6$ & 0.071 \\
\hline MAP & $91.0 \pm 9.9$ & $85.3 \pm 8.6$ & $87.7 \pm 5.3$ & 0.326 \\
\hline CHEOPS & $3.9 \pm 1.3$ & $4.1 \pm 1.2$ & $3.6 \pm 0.9$ & 0.714 \\
\hline OPS & $4.0 \pm 1.3$ & $3.8 \pm 1.1$ & $3.6 \pm 0.8$ & 0.945 \\
\hline \multicolumn{5}{|l|}{ PACU 12th hour } \\
\hline Heart rate & $109.5 \pm 17.2$ & $114.6 \pm 17.0$ & $119.6 \pm 9.9$ & 0.274 \\
\hline MAP & $84.4 \pm 11.2$ & $81.5 \pm 8.5$ & $85.3 \pm 4.8$ & 0.078 \\
\hline CHEOPS & $2.2 \pm 2.0$ & $1.7 \pm 0.9$ & $2.4 \pm 0.5$ & 0.252 \\
\hline OPS & $2.2 \pm 2.1$ & $1.7 \pm 1.5$ & $2.4 \pm 0.5$ & 0.297 \\
\hline Analgesia & $6.1 \pm 3.5$ & $4.7 \pm 2.0$ & $2.1 \pm 1.7$ & $0.000^{* *}$ \\
\hline Rescue analgesia & $6 / 20$ & $5 / 20$ & $12 / 20$ & $0.034^{* *}$ \\
\hline Nausea and vomiting & $0 / 20$ & $0 / 20$ & $8 / 20$ & $0.000^{* *}$ \\
\hline
\end{tabular}

Abbreviations: CHEOPs, modified children's hospital of eastern Ontario pain scale; MAP, mean arterial pressure; OPS, objective pain scale.

${ }^{a}$ One way Anova, ${ }^{* *}$ The mean difference is significant at the 0.05 level.

sure pain in a valid and objective manner in pediatric age group, however there are different ideas suggested in this subject. Various scales are used to assess pain in children.
The most popular ones among them are CHEOPS and OPS. In the present study, it was tried to increase the validity of the assessment using both pain scales. 


\begin{tabular}{|c|c|c|c|c|c|c|c|c|c|}
\hline & $\begin{array}{c}\text { Ketamine + } \\
\text { II/IH Block }\end{array}$ & $\begin{array}{c}\text { LMA + II/IH } \\
\text { Block }\end{array}$ & $\mathbf{P}$ & $\begin{array}{c}\text { LMA+ } \\
\text { Sevorane } \\
\text { (Control) }\end{array}$ & $\begin{array}{c}\text { Ketamine + } \\
\text { II/IH Block }\end{array}$ & $\mathbf{P}$ & $\begin{array}{c}\text { LMA + II/IH } \\
\text { Block }\end{array}$ & $\begin{array}{c}\text { LMA+ } \\
\text { sevorane } \\
\text { (Control) }\end{array}$ & $\mathbf{P}$ \\
\hline \multicolumn{10}{|l|}{ PACU o minute } \\
\hline Heart rate & $106.7 \pm 16.9$ & $111.1 \pm 17.5$ & 0.401 & $122.2 \pm 14.6$ & $106.7 \pm 16.9$ & $0.004^{* *}$ & $111.1 \pm 17.5$ & $122.2 \pm 14.6$ & $0.039^{* *}$ \\
\hline MAP & $85.3 \pm 11.5$ & $79.0 \pm 10.8$ & 0.072 & $89.6 \pm 4.3$ & $85.3 \pm 11.5$ & 0.220 & $79.0 \pm 10.8$ & $89.6 \pm 4.3$ & $0.003^{* *}$ \\
\hline CHEOPS & $1.1 \pm 0.4$ & $0.7 \pm 0.5$ & 0.338 & $3.9 \pm 2.2$ & $1.1 \pm 0.4$ & $0.000^{* *}$ & $0.7 \pm 0.5$ & $3.9 \pm 2.2$ & $0.000^{* *}$ \\
\hline OPS & $0.1 \pm 0.3$ & $0.1 \pm 0.4$ & 0.999 & $3.8 \pm 2.4$ & $0.10 \pm 0.3$ & $0.000^{* *}$ & $0.1 \pm 0.4$ & $3.8 \pm 2.4$ & $0.000^{* *}$ \\
\hline \multicolumn{10}{|l|}{ PACU 30th minute } \\
\hline Heart rate & $109.3 \pm 13.2$ & $113.3 \pm 15.1$ & 0.359 & $122.7 \pm 11.3$ & $109.3 \pm 13.2$ & $0.002^{* *}$ & $113.3 \pm 15.1$ & $122.7 \pm 11.3$ & $0.030^{* *}$ \\
\hline CHEOPS & $0.8 \pm 0.5$ & $0.8 \pm 0.7$ & 0.999 & $3.8 \pm 1.4$ & $0.8 \pm 0.5$ & $0.000^{* *}$ & $0.8 \pm 0.7$ & $3.8 \pm 1.4$ & $0.000^{* *}$ \\
\hline OPS & $0.5 \pm 1.0$ & $0.7 \pm 1.0$ & 0.569 & $3.7 \pm 1.4$ & $0.5 \pm 1.0$ & $0.000^{* *}$ & $0.7 \pm 1.0$ & $3.7 \pm 1.4$ & $0.000^{* *}$ \\
\hline \multicolumn{10}{|l|}{ PACU 60th minute } \\
\hline Heart rate & $110.7 \pm 14.4$ & $113.3 \pm 15.6$ & 0.545 & $121.4 \pm 11.1$ & $110.7 \pm 14.4$ & $0.016^{* *}$ & $113.3 \pm 15.6$ & $121.4 \pm 11.1$ & 0.068 \\
\hline CHEOPS & $1.6 \pm 1.2$ & $1.7 \pm 1.2$ & 0.795 & $3.2 \pm 1.0$ & $1.6 \pm 1.2$ & $0.000^{* *}$ & $1.7 \pm 1.2$ & $3.2 \pm 1.0$ & $0.000^{* *}$ \\
\hline OPS & $1.8 \pm 1.8$ & $2.3 \pm 1.7$ & 0.420 & $3.4 \pm 1.5$ & $1.8 \pm 1.8$ & $0.006^{* *}$ & $2.3 \pm 1.7$ & $3.4 \pm 1.5$ & 0.051 \\
\hline \multicolumn{10}{|l|}{ PACU 2nd hour } \\
\hline Heart rate & $107.6 \pm 15.3$ & $115.7 \pm 14.8$ & 0.061 & $121.9 \pm 9.8$ & $107.6 \pm 15.3$ & $0.001^{* *}$ & $115.7 \pm 14.8$ & $121.9 \pm 9.8$ & 0.148 \\
\hline \multicolumn{10}{|l|}{ PACU 3rd hour } \\
\hline Heart rate & $107.9 \pm 14.9$ & $114.4 \pm 15.4$ & 0.133 & $118.9 \pm 9.9$ & $107.9 \pm 14.9$ & $0.012^{* *}$ & $114.4 \pm 15.4$ & $118.9 \pm 9.9$ & 0.297 \\
\hline \multicolumn{10}{|l|}{ PACU 4th hour } \\
\hline Heart rate & $107.5 \pm 13.3$ & $112.7 \pm 15.5$ & 0.202 & $120.6 \pm 8.7$ & $107.5 \pm 13.3$ & $0.002^{* *}$ & $112.7 \pm 15.5$ & $120.6 \pm 8.7$ & 0.056 \\
\hline CHEOPS & $0.95 \pm 0.9$ & $1.7 \pm 1.0$ & $0.021^{* *}$ & 2.51 .2 & $0.95 \pm 0.9$ & $0.000^{* *}$ & $1.7 \pm 1.0$ & $2.5 \pm 1.2$ & $0.021^{* *}$ \\
\hline OPS & $1.3 \pm 1.2$ & $2.0 \pm 1.1$ & 0.086 & $2.9 \pm 1.6$ & $1.3 \pm 1.2$ & $0.000^{* *}$ & $2.0 \pm 1.1$ & $2.9 \pm 1.6$ & $0.038^{* *}$ \\
\hline \multicolumn{10}{|l|}{ PACU 6th hour } \\
\hline Heart rate & $108.6 \pm 15.2$ & $115.6 \pm 15.9$ & 0.141 & $123.6 \pm 12.2$ & $108.6 \pm 15.2$ & $0.002^{* *}$ & $115.6 \pm 15.9$ & $123.6 \pm 12.2$ & 0.091 \\
\hline CHEOPS & $1.7 \pm 1.5$ & $2.5 \pm 2.1$ & 0.152 & $3.6 \pm 1.9$ & $1.7 \pm 1.5$ & $0.001^{* *}$ & $2.5 \pm 2.1$ & $3.6 \pm 1.9$ & 0.065 \\
\hline OPS & $1.4 \pm 1.8$ & $2.2 \pm 1.5$ & 0.239 & $4.0 \pm 2.5$ & $1.4 \pm 1.8$ & $0.002^{* *}$ & $2.2 \pm 1.5$ & $4.0 \pm 2.5$ & $0.004^{* *}$ \\
\hline Analgesia & $6.1 \pm 3.5$ & $4.7 \pm 2.0$ & 0.125 & $2.1 \pm 1.7$ & $6.1 \pm 3.5$ & $0.000^{* *}$ & $4.7 \pm 2.0$ & $2.1 \pm 1.7$ & $0.005^{* *}$ \\
\hline Rescue analgesia & $6 / 20$ & $5 / 20$ & 0.738 & $12 / 20$ & $6 / 20$ & $0.047^{* *}$ & $5 / 20$ & $12 / 20$ & $0.021^{* *}$ \\
\hline $\begin{array}{l}\text { Nausea and } \\
\text { vomiting }\end{array}$ & $0 / 20$ & $0 / 20$ & 0.999 & $8 / 20$ & $0 / 20$ & $0.000^{* *}$ & $0 / 20$ & $8 / 20$ & $0.000^{* *}$ \\
\hline
\end{tabular}

In all anesthesia methods, to which $\mathrm{II} / \mathrm{IH}$ was added, (general anesthesia/regional anesthesia/sedation), better and effective postoperative analgesia, lower pain scores and longer painlessness period were observed in the group to which the block was applied (6,11-14). Parallel to the literature, in the present study, the longest analgesia duration was observed in the ketamine-supported II/IH block group and this period was determined as $6.1 \pm 3.5$ hours. Similarly, the duration of analgesia in the LMA + sevoflurane $+\mathrm{II} / \mathrm{IH}$ block group was significantly higher compared to the group treated only with sevoflurane. Pain scores were lower in both block groups and HR and MAP were higher in the group with no block, and analgesic need and nauseavomiting rate were higher in the group without block.

\subsection{Conclusion}

In this study, it was determined that II/IH block added to general anesthesia or sedation in pediatric lower abdominal surgery reduced the need for intraoperative anes- thesia, provided a more stable intraoperative hemodynamics and analgesia, and provided less pain scores, longer analgesia duration and less analgesia need in the postoperative period. Also, it was observed that it caused a better PACU process and less nausea and vomiting. It is thought that ketamine-supported II/IH block anesthesia can be used alone as a successful anesthetic technique in pediatric lower abdominal surgery.

\section{References}

1. Lacroix F. Epidemiology and morbidity of regional anaesthesia in children. Curr Opin Anaesthesiol. 2008;21(3):345-9. doi: 10.1097/ACO.ob013e3282ffabc5. [PubMed: 18458552].

2. Bhattarai BK, Rahman TR, Sah BP, Tuladhar UR. Analgesia after inguinal herniotomy in children: combination of simplified (Single Puncture) ilioinguinal and iliohypogastric nerve blocks and wound infiltration vs. caudal block with $0.25 \%$ bupivacaine. Kathmandu Univ Med J (KUMJ). 2005;3(3):208-11.

3. Zanaboni S, Krauss B, Buscaglia R, Montagnini C, Gratarola A, Gualino $\mathrm{J}$, et al. Changes in respiratory and hemodynamic parameters dur- 
ing low-dose propofol sedation in combination with regional anesthesia for herniorrhaphy and genitourinary surgery in children. PaediatrAnaesth. 2007;17(10):934-41. doi:10.1111/j.1460-9592.2007.02299.x. [PubMed: 17767628].

4. Abdellatif AA. Ultrasound-guided ilioinguinal/iliohypogastric nerve blocks versus caudal block for postoperative analgesia in children undergoing unilateral groin surgery. Saudi J Anaesth. 2012;6(4):36772. doi: 10.4103/1658-354X.105868. [PubMed: 23493806]. [PubMed Central: PMC3591556].

5. Seyedhejazi M, Sheikhzadeh D, Adrang Z, Rashed FK. Comparing the analgesic effect of caudal and ilioinguinal iliohypogastric nerve blockade using bupivacaine-clonidine in inguinal surgeries in children 2-7 years old. Afr J Paediatr Surg. 2014;11(2):166-9. doi: 10.4103/0189-6725.132821. [PubMed: 24841020].

6. Mohamed MM, Kamal MH. Comparison of postoperative analgesia of ultrasound-guided ilioinguinal/iliohypogastric nerve block versus ultrasound-guided TAP block for pediatric inguinal hernia repair. Ain Shams J Anesthiol. 2015;8(4):658-63.

7. Polaner DM, Taenzer AH, Walker BJ, Bosenberg A, Krane EJ, Suresh $S$, et al. Pediatric Regional Anesthesia Network (PRAN): a multiinstitutional study of the use and incidence of complications of pediatric regional anesthesia. Anesth Analg. 2012;115(6):1353-64. doi: 10.1213/ANE.0b013e31825d9f4b. [PubMed: 22696610].

8. Willschke H, Marhofer P, Machata AM, Lonnqvist PA. Current trends in paediatric regional anaesthesia. Anaesthesia. 2010;65 Suppl 1:97-104. doi: 10.1111/j.1365-2044.2010.06242.x. [PubMed: 20377551].
9. Alsadek WM, Al-Gohari MM, Elsonbaty MI. Ultrasound guided TAP block versus ultrasound guided caudal block for pain relief in children undergoing lower abdominal surgeries. Egyptian J Anaesthesia. 2015;31(2):155-60.

10. Kim SH, Chun DH, Chang CH, Kim TW, Kim YM, Shin YS. Effect of caudal block on sevoflurane requirement for lower limb surgery in children with cerebral palsy. Paediatr Anaesth. 2011;21(4):394-8. doi: 10.1111/j.1460-9592.2011.03530.x. [PubMed: 21299684].

11. Nan Y, Zhou J, Ma Q, Li T, Lian QQ, Li J. [Application of ultrasound guidance for ilioinguinal or iliohypogastric nerve block in pediatric inguinal surgery]. Zhonghua Yi Xue Za Zhi. 2012;92(13):873-7. [PubMed: 22781525].

12. Toivonen J, Permi J, Rosenberg PH. Analgesia and discharge following preincisional ilioinguinal and iliohypogastric nerve block combined with general or spinal anaesthesia for inguinal herniorrhaphy. Acta Anaesthesiol Scand. 2004;48(4):480-5. doi: 10.1111/j.13996576.2004.00346.x. [PubMed: 15025612].

13. Santos Gde C, Braga GM, Queiroz FL. Assessment of postoperative pain and hospital discharge after inguinal and iliohypogastric nerve block for inguinal hernia repair under spinal anesthesia: a prospective study. Rev Assoc Med Bras. 2011;57(5):545-9.

14. Gurkan I, Utebey G, Ozlu O. [Comparison of ilioinguinaliliohypogastric nerve block versus spinal anesthesia techniques for single sided inguinal herniorrhaphy]. Agri. 2013;25(3):108-14. doi: 10.5505/agri.2013.95866. [PubMed: 24104532]. 